OnLine Journal of Biological Sciences 10 (2): 73-83, 2010

ISSN 1608-4217

(C) 2010 Science Publications

\title{
Summarizing Spatial Distribution Density, Movement Patterns and Food Resources to Study the Impacts of Logging and Forest Conversion on Orang-utan Population
}

\author{
${ }^{1}$ Raymond Alfred, ${ }^{1}$ Koh Pei Hue, ${ }^{1}$ Lee Shan Khee and ${ }^{2}$ Rayner Alfred \\ ${ }^{1}$ Borneo Species Programme, WWF-Malaysia, 1-6-W11, 6th Floor, CPS Tower, \\ Centre Point Complex, Jalan Centre Point, 80000 Kota Kinabalu, Sabah, Malaysia \\ ${ }^{2}$ School of Engineering and Information Technology, University Malaysia Sabah, \\ Locked Bag 2073, 88999 Kota Kinabalu, Sabah, Malaysia
}

\begin{abstract}
Problem statement: Orang-utan is classified as a totally protected species and is listed as an endangered species in Borneo. The survival of this species is highly dependent on the existence and quality of the lowland forest of Sabah. However, most of the pristine habitats in the lowland area have been converted into other land use activities such as a large scale plantation. This is due to the fact that most of the lowland forests are facing a continuous degradation process that will decrease its commercial value when it comes to generating revenue to the state government. Thus, the efforts to restore the forest are very vital. The main objectives of this study include establishing the relative spatial distribution of orang-utan in order to assess and determine the effects of the forest conversions in four main wild orang-utan population landscape, demonstrating the orang-utan population movement pattern as a response to the heavy logging activities and also quantifying the effect of logging activities on the status of food trees or plant species for orang-utan in their current forest habitat. Approach: In this research, relevant features are constructed in order to study the impacts of logging and forest conversion on Orang-utan population in Borneo. These features include aerial surveys and feeding behaviors. An aerial survey on orang-utan's nest in four out of six main forest habitats for orang-utan in Sabah has been conducted between May 2005 and June 2009 in order to map the relative distribution and spatial density of the orang-utans. This is conducted in order to determine the impacts of the forest conversion for the last 20 years upon the orang-utan spatial distribution. In this project, three series of aerial surveys, covering Malua Forest Reserve, have been conducted to demonstrate the dynamic movement and habitat utilization by the orang-utan population, due to the logging activities within the forest habitat. A long term observation of the orang-utan feeding behavior in the degraded forest in North Ulu Segama (NUS) has been also conducted to determine their feeding ecology in a logged over forest. Results: This study suggested that (i) forest conversion and logging activities have effects on the orang-utan habitat utilization and movement pattern; (ii) due to the influx of the forest conversion, some of the orang-utan in the forest reserve is concentrated in certain area, adjacent to the boundary of the forest reserve due to their movement limitation by the river network; (iii) the orang-utan population in degraded forest of NUS consumed almost different species of food plants in 2009, compared to year 1974. Conclusion: These results demonstrated that forest conversion and unsustainable logging activities are the main threat for the orang-utans conservation in Sabah. Therefore, the conservation of orang-utan populations are not guaranteed by the establishment of more protected area, but by ensuring that more forest habitats can be managed in sustainable way in order to avoid further forest degradation and to ensure their habitats remain connected to the large forest landscape.
\end{abstract}

Key words: Orang-utan, forest logging, forest conversion, spatial distribution, aerial survey

\section{INTRODUCTION}

Orang-utan (P. pygmaeus) is classified as a totally protected species under Part 1 of Schedule 1, Section 25 (1) of Sabah's Wildlife Conservation Enactment 1997 and is listed as an endangered species in the IUCN Red List of Threatened Species. The subspecies and any products derived from it are prohibited from international trade under CITES where it appears under Appendix 1 of the agreement.

Corresponding Author: Raymond Alfred, School of Engineering and Information Technology, University Malaysia Sabah, Locked Bag 2073, 88999 Kota Kinabalu, Sabah, Malaysia 


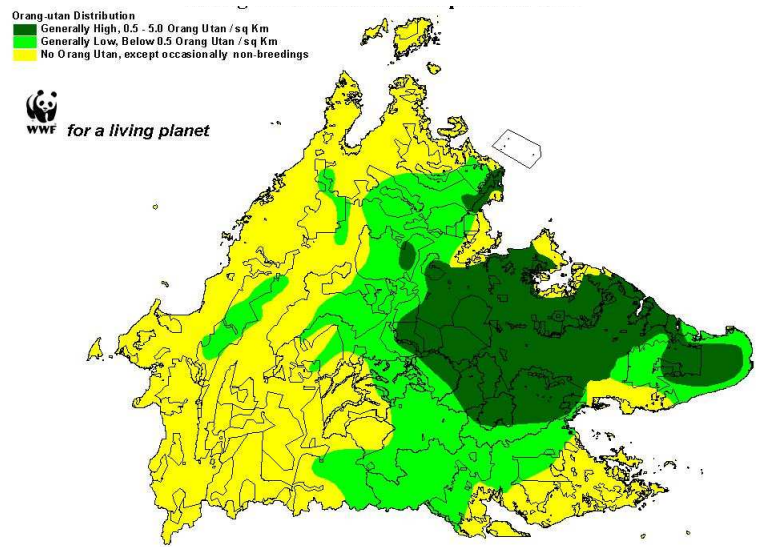

Fig. 1: Orang-utan distribution map in 1987-1988

It was estimated by WWF-Malaysia in 1988 that the population of orang-utan in Sabah is ranging from 10,000-11,000 (Fig. 1) and followed by another statewide survey carried out by HUTAN in year 2002-2003, which indicated that the orang-utan population in Sabah is approximately 13,192 individuals. (95\% confidence Intervals: 7,210-23,786) (Ancrenaz et al., 2005).

Currently, there are at least six main forest areas of special importance to orang-utans in the State of Sabah is identified. They are listed as shown below:

- Ulu Segama Malua area plus adjacent forests of Danum Valley Conservation. (about 3,000 $\mathrm{km}^{2}$ ) This area represents the "Upper Kinabatangan and Segama river catchments" landscape mentioned in the "WWF's Species Action Plan for the Conservation of Orang-utans (Pongo abeli and Pongo pygmaeus) in the wild"; It is of vital importance that this entire area be retained under natural forest management in order to secure the long-term survival of the orang-utan in Malaysia

- Kinabatangan North (about $1,400 \mathrm{~km}^{2}$ ) This area includes Deramakot Forest Reserve (the only natural forest in Malaysia granted international recognition under Forest Stewardship Council principles and criteria for production of timber under "sustainable management") plus the adjacent Segaliud-Lokan and Tangkulap Forest Reserves, both also timber production forests under sustainable forest management plans

- Tabin Wildlife Reserve $\left(1,200 \mathrm{~km}^{2}\right)$ Tabin Wildlife Reserve comprises a rectangular area, in the centre of the Dent Peninsula, north-east of Lahad Datu and lying South of the lower reaches of the Segama River and North of the Silabukan Forest Reserve. Tabin is a forested area almost totally surrounded by land alienated for oil palm plantations. Tabin Wildlife Reserve comprises three different categories of forest reserve under the Forests
Enactment, 1968 as amended in 1984 and 1992, viz., Class VII-Wildlife Reserve, Class I-Protection Forest Reserve and Class VI-Virgin Jungle Reserve

- Lower Kinabatangan River Region (Kinabatangan Corridor of Life) (about $400 \mathrm{~km}^{2}$ )-5 blocks of forest reserves in and adjacent to the Kinabatangan floodplain, includes Gomantong Virgin Jungle Reserve, Supu Virgin Jungle Reserve, Materis Virgin Jungle Reserve, Bod Tai Virgin Jungle Reserve and Pangi Virgin Jungle Reserve.

- Kulamba Wildlife Reserve (including Kretam Virgin Jungle Reserve) with an area approximately $210 \mathrm{~km}^{2}$ ), mostly freshwater swamp forest. $30 \%$ of the area in Kulamba FR was burnt in 1987

- Central Forest area (about, which consist of Kuamut Forest Reserve $\left(1,152 \mathrm{~km}^{2}\right)$, Gunung Rara Forest Reserves $\left(2,154 \mathrm{~km}^{2}\right)$, Kalabakan Forest Reserve (about 2,239 $\mathrm{km}^{2}$ where $800 \mathrm{~km}^{2}$ is already converted into oil palm and industrial tree plantation), Batu Timbang Virgin Jungle Reserve $\left(2.6 \mathrm{~km}^{2}\right)$, Ulu Sungai Napagon Virgin Jungle Reserve $\left(5.22 \mathrm{~km}^{2}\right)$, Imbok Virgin Jungle Reserve $\left(1.24 \mathrm{~km}^{2}\right)$, Burod Durod Virgin Jungle Reserve $\left(16.52 \mathrm{~km}^{2}\right)$ and Brantian-Tantulit Virgin Jungle Reserve $\left(21.54 \mathrm{~km}^{2}\right)$

All six populations are potentially viable as long as the connectivity and forest habitat quality in the mentioned habitats can be maintained and restored. If the currently damaged forest habitat in the lowland parts of these six areas can be restored, secured and managed sustainably, it is anticipated that a population of at least 10,000 wild orang-utans can be sustained long-term in Sabah. The main goals of this study are:

- To establish the relative spatial distribution of orang-utan in order to assess and determine the effects of the forest conversions in four main wild orang-utan population landscape

- To demonstrate the orang-utan population movement pattern as a response to the heavy logging activities

- To quantify the effect of logging activities on the status of food trees or plant species for orang-utan in their current forest habitat

\section{MATERIALS AND METHODS}

The establishment of spatial distribution of orangutan density in four main forest habitats: Aerial survey has been carried out to gather the spatial distribution pattern of the orang-utan population in four main forest habitats. Figure 2a-d shows how the spatial distribution pattern of orang-utan population is gathered. 


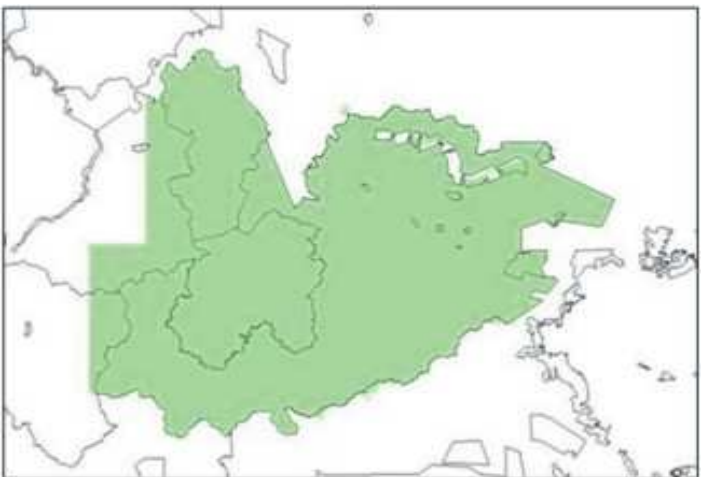

(a)

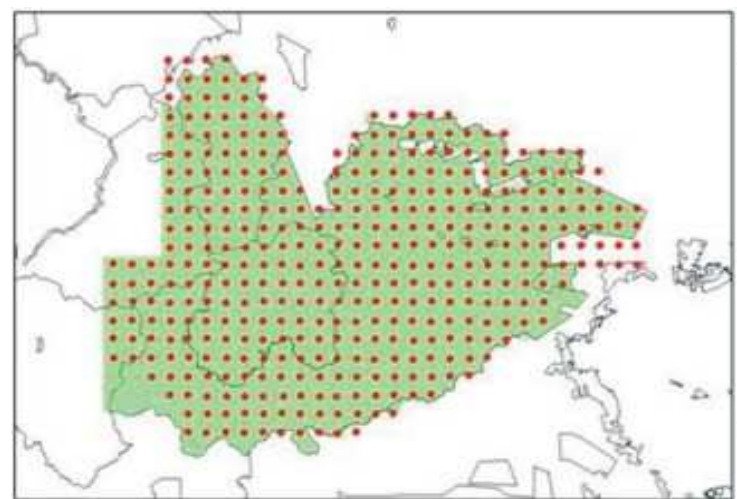

(c)

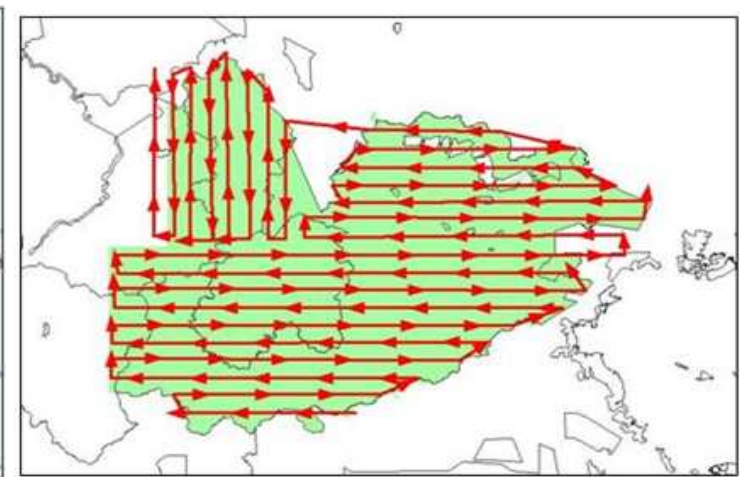

(b)

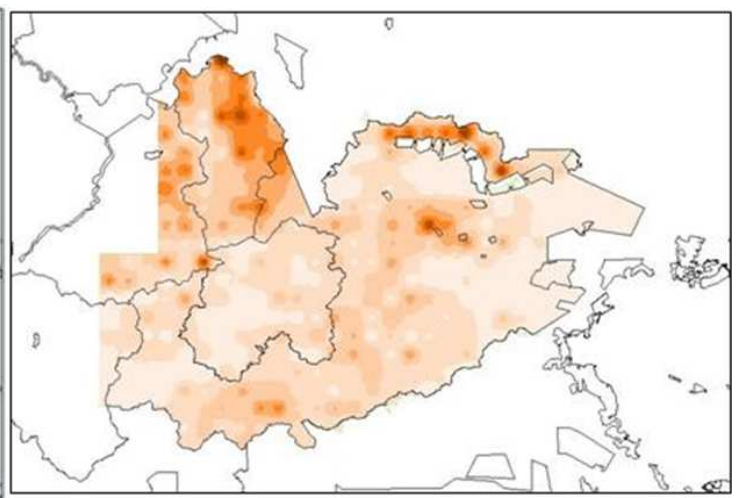

(d)

Fig. 2: Producing the spatial distribution pattern of orang-utan population. (a) Study area: Ulu Segama Malua forest reserve, (b) system aerial survey routes, (c) developed topology representing nest abundance, (d) using surface modeling to map the spatial distribution

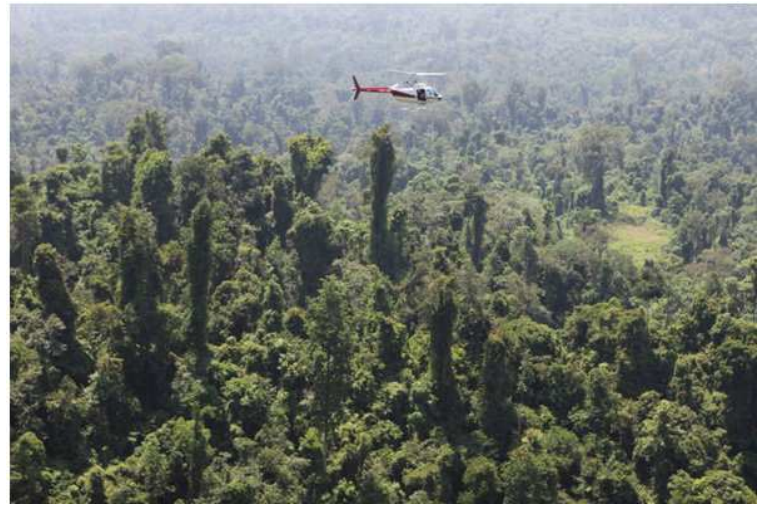

Fig. 3: Photo shows the height of the helicopter from the tree canopy during the aerial survey

Figure 2a shows one of the key habitats for the orangutan in Sabah, Ulu Segama Malua Forest Reserve. An Aerial survey was carried out in this area using helicopter (Bell 206 Jet Ranger). We followed a systematic stratified sampling pattern using parallel line-transects, at $3 \mathrm{~km}^{2}$ interval spacing (Fig. $2 \mathrm{~b}$ ). The helicopter speed was maintained ranging between 70 and $90 \mathrm{~km} \mathrm{~h}^{-1}$ depending on the condition of the terrain elevation (Fig. 3). The flying elevations are varied from $70-80 \mathrm{~m}$ (depending on the terrain elevation) above the forest canopy. Sighting of orang-utan nests is recorded using Garmin GPSmap 76CSx, by two people who are sitting at the back left and right seat of the helicopter, while another person (co-pilot) sitting next to the helicopter pilot assisting the navigation part and taking photo on the forest condition.

After the aerial survey is done, the locations of the nests from the GPS handheld are downloaded directly using the Map Garmin software. The orangutan nest data is manipulated using the GIS in order to develop the value of each grid (Fig. 2c). The value of the grid is actually generated based on aerial orang-utan nest density index (orang-utan's nest per $\mathrm{km}, \mathrm{n}^{\mathrm{a}} / \mathrm{km}$, where $\mathrm{n}^{\mathrm{a}}=$ number of orang-utan's nest sighted and recorded during the aerial survey). 


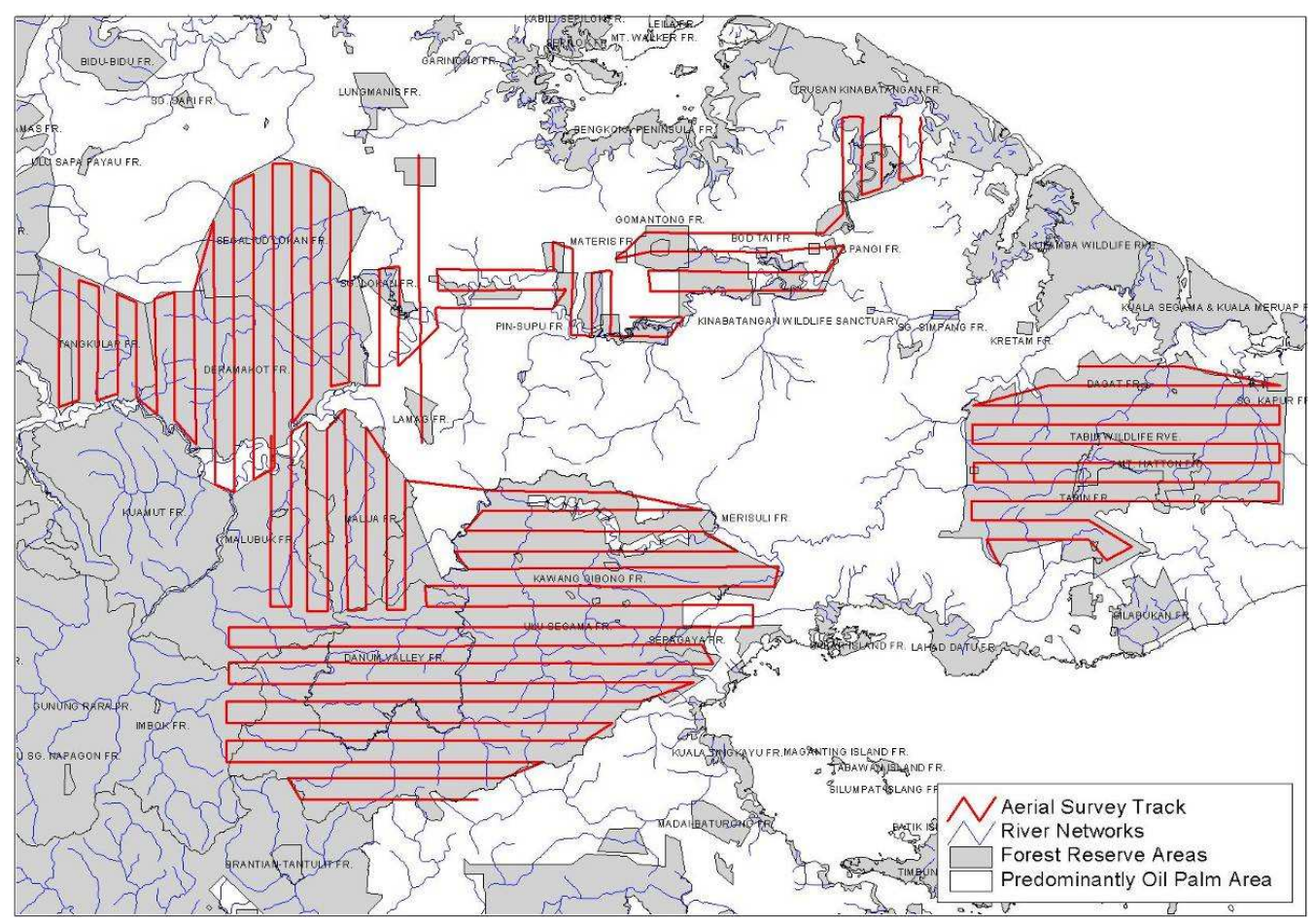

Fig. 4: The pattern of aerial survey track conducted in four main area of orang-utan habitat in Sabah

Then, by using the value of each grid in the GIS system, the grid surface interpolation method is used (Buyya and Murshed, 2002), to model the nest density pattern in the study area (Fig. 2d). Figure 4 shows the pattern of the aerial survey being conducted in the four main areas of orang-utan habitats in Sabah, namely (i) Ulu Segama Malua area plus adjacent forests of Danum Valley Conservation Area, (ii) Kinabatangan North (Segaliud Lokan, Deramakot and Tangkulap), (iii) Tabin Wildlife Reserve and (iv) Lower Kinabatangan River Region.

The effects of forest conversion on the orang-utan's distribution in the forest landscape: The output of the spatial orang-utan distribution is used to facilitate the assessment of the effect of the forest conversion on the orang-utan population. The orang-utans populations pattern in Tabin, North Ulu Segama, Malua Forest Reserve, Deramakot Forest Reserve and Segaliud Lokan Forest Reserve are reviewed visually based on the relative distribution pattern derived from the aerial survey in order to address the impact of the forest conversion.

The impacts of logging activities on the orang-utan's movement and habitat utilization: This assessment is carried out in Malua Forest Reserve (connected to
Kuamut Forest Reserve at the west part and Ulu Segama Forest at the south part). The west part of Malua Forest Reserve is just recently logged heavily in early 2005, as interpreted visually using the SPOT Satellite Image with $2.5 \mathrm{~m}$ resolution.

Malua Forest Reserve is a non-fragmented forest reserve and this forest is connected to the larger forest landscape namely Kuamut (at the west part) and Ulu Segama Forest Reserve (at the southern and eastern part). Three series of aerial survey were conducted in September 2005, June 2006 and January 2007, by using the same helicopter type, same observers and same flying route. The spatial distribution of the orang-utan's population pattern for each survey is mapped and assessed.

Determination of the logging activities' effect on the status of food trees or plant species for orang-utan in the study area: The behavior observation programme was established to observe the orang-utan's behavior, including recording the orang-utan food trees/plants in the North Ulu Segama (NUS). At the end of 24 months, a list of food trees/plants species is compiled and compared to the previous compilation of food trees/plants recorded in 1974 by McKinnon (1974) from the vicinity area. The list of trees or plants consumed by the orang-utan that is compiled during 
this study (2009) is compared with the list of trees/plants recorded in 1974 s, in order (i) to determine the number of percentage of tree species that is not consumed any for by the orang-utan in the study area and also (ii) to determine the number or list of tree species that is current taken by orang-utan that is never recorded in Mckinnon's study.

\section{RESULTS}

The establishment of spatial distribution of orangutan density in four main forest habitats: Figure 5 shows the spatial distribution of the orang-utan population in four key habitats. Table 1 shows the mean aerial index (detection index of the orang-utan nest from the aerial view).

The highest orang-utan's nest aerial index is recorded in the Kinabatangan North area (31.46), followed by Tabin Wildlife Reserve (7.22) and Lower Kinabatangan (6.77). Ulu Segama Malua Forest Reserve (including Danum Valley Conservation Area has an aerial index at 4.73. The Table 2 and Fig. 6 show the status of the orang-utan density based on the topography pattern.

Based on the data shown in Fig. 6, high density pattern of orang-utan is recorded in the area with topography below $300 \mathrm{~m}(98.9 \%)$ and also recorded in the area with topography ranging from $300-750 \mathrm{~m}$. No orang-utan's recorded in the area with topography more than $1,000 \mathrm{~m}$ in the study area.

The impact of the logging activities upon the orangutan's movement and habitat utilization: Figure 7a-c illustrate the relative distribution density of orang-utan based on orang-utan nest density survey conducted in September 2005, June 2006 and January 2007 respectively. The detection index of the aerial survey for each survey in secondary forest and heavily logged forest is shown in the Table 3.

The value of detection index represents the degree of orang-utan nest detection from the aerial during the survey period.

Determining logging activities' effects on the status of food trees or plant species for orang-utan in the studied areas: McKinnon (1974) carried out the orangutan behavioral study in North Ulu Segama in 1974 where he had recorded at least 97 species of food trees or plants, consumed by the orang-utans. However, a study carried out by WWF-Malaysia in 2009, using scan methods (Altmann, 1974), shows that only 71 species of food trees or plants in North Ulu Segama, is consumed by the orang-utans. (Table 4: List of Food Plants/Trees (based on genus) recorded in year 2009 and 1974).

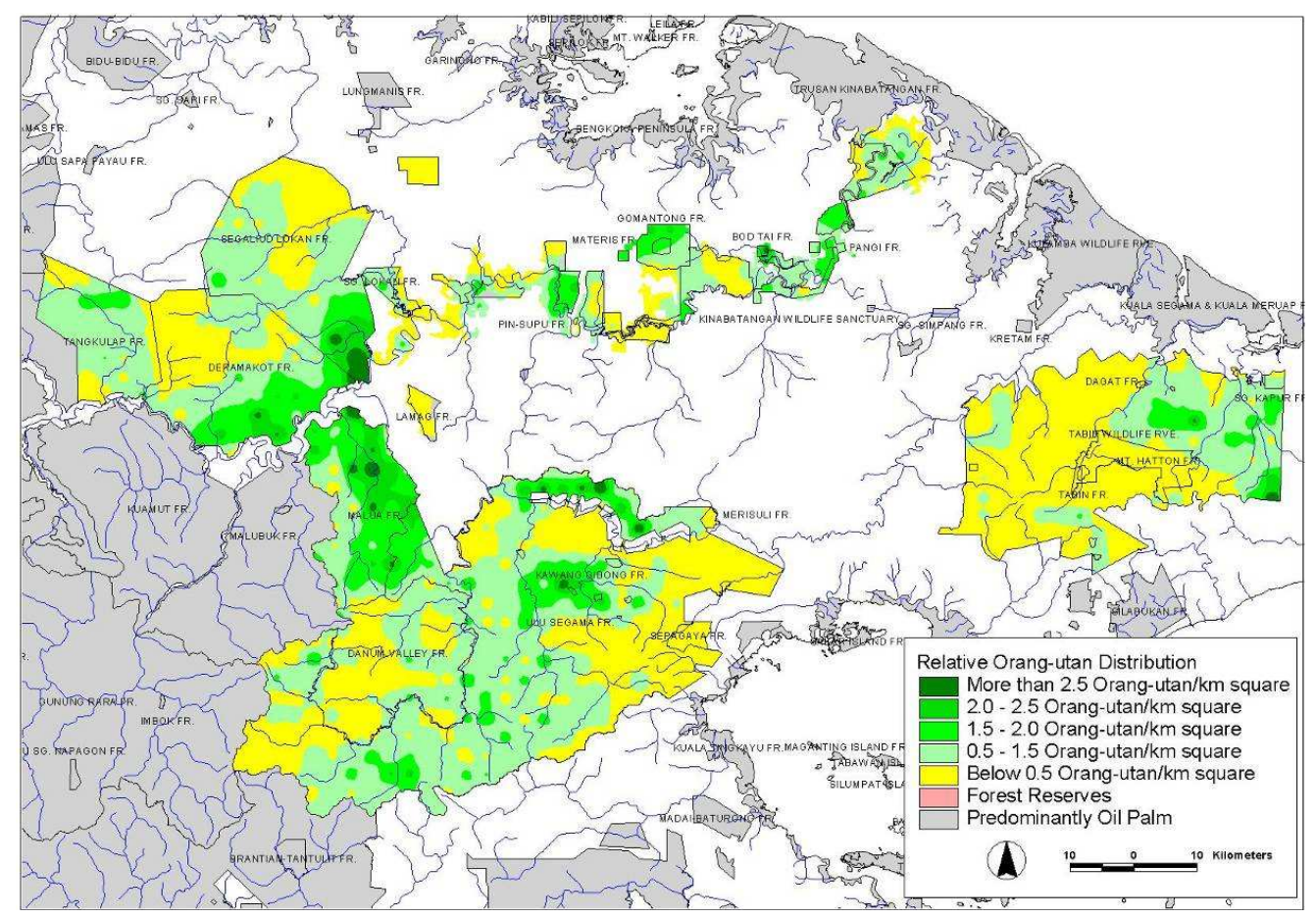

Fig. 5: Spatial distribution of orang-utan population in four key habitats 
OnLine J. Biol. Sci., 10 (2): 73-83, 2010

Table 1: Aerial Index for the orang-utan nest in four key orang-utan habitat

\begin{tabular}{lllc}
\hline & $\begin{array}{l}\text { Aerial survey } \\
\text { track's distance } \\
(\mathrm{km})\end{array}$ & $\begin{array}{l}\text { Number of } \\
\text { orang-utan } \\
\text { nest } \\
\text { detected }\end{array}$ & $\begin{array}{l}\text { Mean aerial } \\
\text { index (nest } \\
\left.\mathrm{km}^{-1}\right)\end{array}$ \\
\hline $\begin{array}{l}\text { Key habitat } \\
\begin{array}{l}\text { Ulu Segama Malua area } \\
\text { Including Danum Valley) }\end{array}\end{array}$ & $1,215.19$ & 5.753 & 4.73 \\
$\begin{array}{l}\text { Kinabatangan North } \\
\text { (Segaliud Lokan, }\end{array}$ & 531.38 & 16.718 & 31.46 \\
$\begin{array}{l}\text { Deramakot and Tangkulap) } \\
\text { Tabin Wildlife Reserve }\end{array}$ & 439.21 & 3.171 & 7.22 \\
Lower Kinabatangan & 434.14 & 2.941 & 6.77 \\
\hline
\end{tabular}

Table 2: Status of the orang-utan density based on the topography pattern

\begin{tabular}{|c|c|c|c|c|c|}
\hline Topography & $\begin{array}{l}\text { Above } 2.5 \\
\text { Orang-utan } \\
\mathrm{km}^{2}(\%)\end{array}$ & $\begin{array}{l}2.0-2.5 \\
\text { Orang-utan } \\
\mathrm{km}^{2}(\%)\end{array}$ & $\begin{array}{l}1.5-2.0 \\
\text { Orang-utan } \\
\mathrm{km}^{2} \text { pattern } \\
(\%)\end{array}$ & $\begin{array}{l}0.5-1.5 \\
\text { Orang-utan } \\
\mathrm{km}^{2}(\%)\end{array}$ & $\begin{array}{l}\text { Below } 0.5 \\
\text { Orang-utan } \\
\mathrm{km}^{2}(\%)\end{array}$ \\
\hline $0-300$ & 98.9 & 94.8 & 84.9 & 70.3 & 74.3 \\
\hline $300-750$ & 1.1 & 5.2 & 14.9 & 28.6 & 22.4 \\
\hline $750-1000$ & 0.0 & 0.0 & 0.2 & 1.1 & 3.0 \\
\hline $1000-1250$ & 0.0 & 0.0 & 0.0 & 0.0 & 0.4 \\
\hline $1250-1500$ & 0.0 & 0.0 & 0.0 & 0.0 & 0.0 \\
\hline
\end{tabular}

Table 3: Aerial index (nest $/ \mathrm{km}$ ) of the orang-utan's nest in Malua Forest Reserve in three different time series

\begin{tabular}{lccc}
\hline $\begin{array}{l}\text { Date of aerial } \\
\text { survey }\end{array}$ & $\begin{array}{c}\text { Overall } \\
(\text { nest km}\end{array}$ kn $\left.^{-1}\right)$ & $\begin{array}{c}\text { In secondary } \\
\text { forest }(\text { nest km }\end{array}$ & $\begin{array}{c}\text { In recently logged } \\
\text { forest }(\text { nest km }\end{array}$ \\
\hline 14 September 2005 & $11.05 \pm 0.82$ & $11.41 \pm 0.88$ & $8.44 \pm 2.06$ \\
04 June 2006 & $6.05 \pm 0.53$ & $6.71 \pm 0.58$ & $6.58 \pm 1.34$ \\
18 January 2007 & $18.08 \pm 1.52$ & $18.42 \pm 1.64$ & $14.08 \pm 3.81$ \\
\hline
\end{tabular}

Table 4: List of food plants/trees recorded in 1974 and 2009

Food plants/trees

Aglaia

Alangium

Amoora

Arthocarpus

Artobotrys

Baccaurea

Barringtonia

Bauhinie

Calamus

Cananga

Canarium

Carallia

Castanopsis

Coelygyne

Combretum

Crudia

Dacrycarpus

Dialium

Dillenia

Dinochloa

Diospyros

Dipterocarpus

Dischidia

Dracontomelon

Dryobalanus

Drypetes

Duabanga

Durio

Dysoxylon

Endospermum

Eria

\begin{tabular}{|c|c|}
\hline 1974 & 2009 \\
\hline 2 & 1 \\
\hline 1 & 0 \\
\hline 0 & 1 \\
\hline 3 & 4 \\
\hline 1 & 0 \\
\hline 1 & 1 \\
\hline 1 & 1 \\
\hline 2 & 0 \\
\hline 0 & 1 \\
\hline 0 & 1 \\
\hline 1 & 2 \\
\hline 1 & 0 \\
\hline 0 & 1 \\
\hline 0 & 1 \\
\hline 0 & 1 \\
\hline 0 & 1 \\
\hline 1 & 0 \\
\hline 0 & 2 \\
\hline 0 & 2 \\
\hline 1 & 1 \\
\hline 1 & 2 \\
\hline 0 & 3 \\
\hline 0 & 1 \\
\hline 0 & 2 \\
\hline 0 & 1 \\
\hline 0 & 1 \\
\hline 1 & 0 \\
\hline 1 & 3 \\
\hline 0 & 1 \\
\hline 1 & 0 \\
\hline 0 & 1 \\
\hline
\end{tabular}

Table 4: Continue

Etlingera

Eugenia

Euphoria

Eusideroxylon

Ficus

Fordia

Gracinia

Glycomis

Gnetum

Goniothalamus

Homalanthus

Hydnocarpus

Intsia

Jacquemontia

Jarandowsonia

Knema

Koordersiodendron

Korthalsia

Langsium

Leea

Lithocarpus

Macaranga

Madhuca

Mastersia

Merope

Merrimia

Michelia

Microccos

Milletia

Myristica

Nauclea

Neolamarckia

Neonauclea

Neouvaria

Nephelium

Octomelas

Oncosperma

Palaquin

Paranephelium

Parartocarpus

Paraserianthes

Parashorea

Phanera

Piper

Pleiocarpidia

Poikilospermum

Polyalthia

Pometia

Prunus

Pternandra

Pterospermum

Santiria

Saraca

Sarcotheca

Semecarpus

Shorea

Similax

Sindora

Spatholobus

Strychnos

Strychnosis

Sympetalandra

Symplocos

Talanma

Trema

Uncaria

Willughbeia

Xylopia

Zingeberacea

Zizyphus

Tota 


\section{DISCUSSION}

Spatial distribution of orang-utan density in four main forest habitats: Previous study on orang-utan by Rijksen (1982) and Andrea in the more recent year (2004) suggest that orang-utans are primarily found in lowland habitats and appear to prefer two major geomorphologic landscapes: Freshwater fringe (floodplain, swamp, or alluvial valley) and adjacent upland regions (usually neighboring foothills), or any habitat where sources of water is not a problem. Such a mosaic of habitats buffers seasonal variations of food availability in the forest and allows the animals to acquire sufficient sources of food throughout the year.

Orang-utan densities decreases with a rise in altitude and only small populations are found above $1,000 \mathrm{~m}$ above mean sea level. In most cases, encounters in the highlands are of migrating from one area to another. This altitudinal limitation may be a direct function of food sources, as the density of fruit bearing trees decreases sharply at higher altitudes. (Johnson et al. 2004) As with most animals, orangutans are sensitive to habitat disturbance and their densities drop sharply in and around intensively logged forests, where forest canopy is fragmented through the establishment of logging road, feeder road and $\log$ landing site. From the spatial distribution of orang-utan, higher orang-utan distribution pattern in flat land form especially in lowland dipterocarp forest

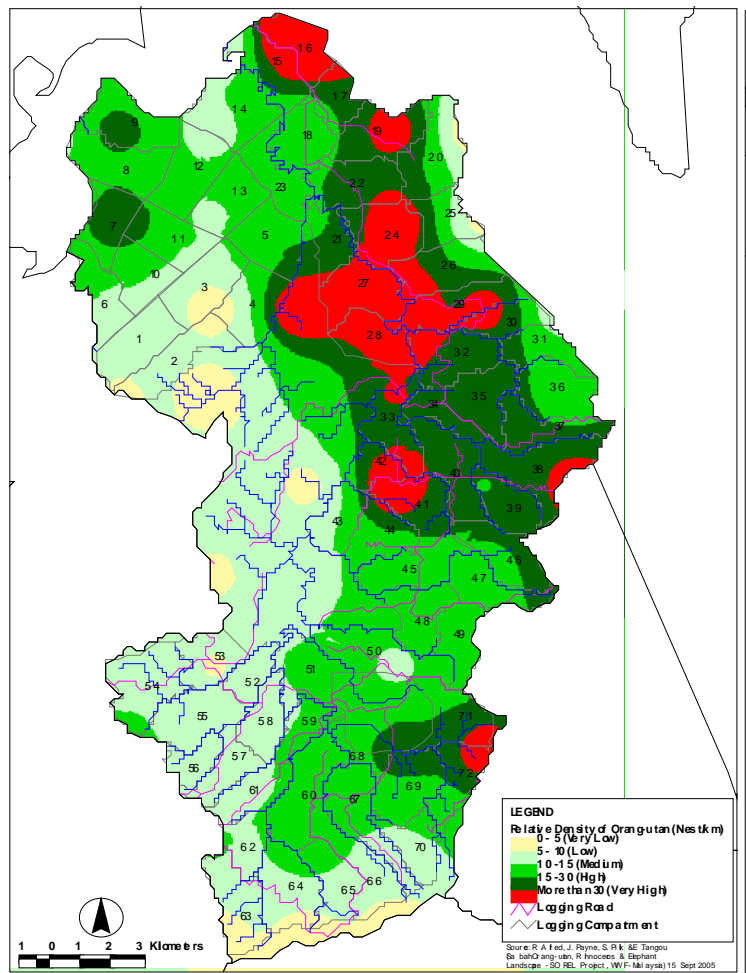

(a) compared to the upland forest (more than $750 \mathrm{~m}$ of elevation). This is mainly due to the differences in forest type. Payne (1987) suggested that orang-utan distribution and numbers are limited by one or more factors other than forest type. Possible factors include:

- Illegal killing of orang-utan due to conflict or hunting activities: Illegal killing of orang-utan may cause local extinction of orang-utans, although these activities cannot be accounted entirely, and past hunting in areas now uninhabited by people could possibly have caused the present-observed low density of orang-utan in the study area

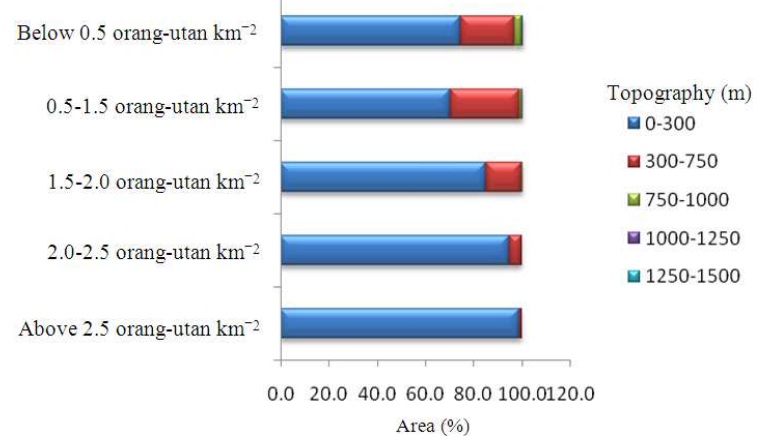

Fig. 6: Percentage of area based on the density patter

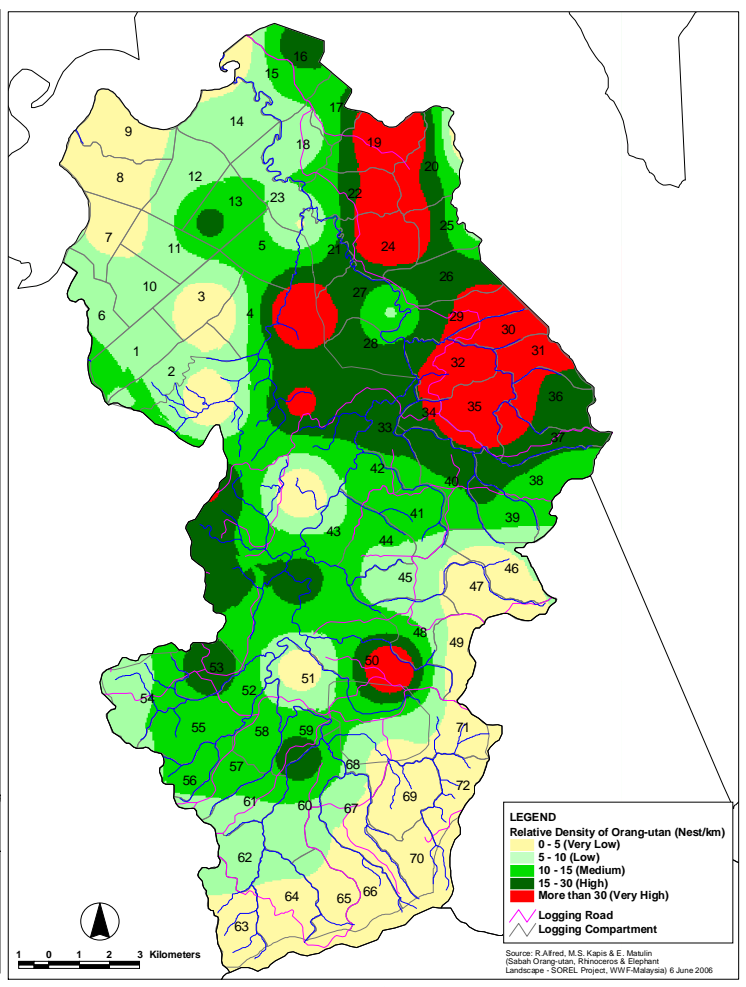

(b) 
OnLine J. Biol. Sci., 10 (2): 73-83, 2010

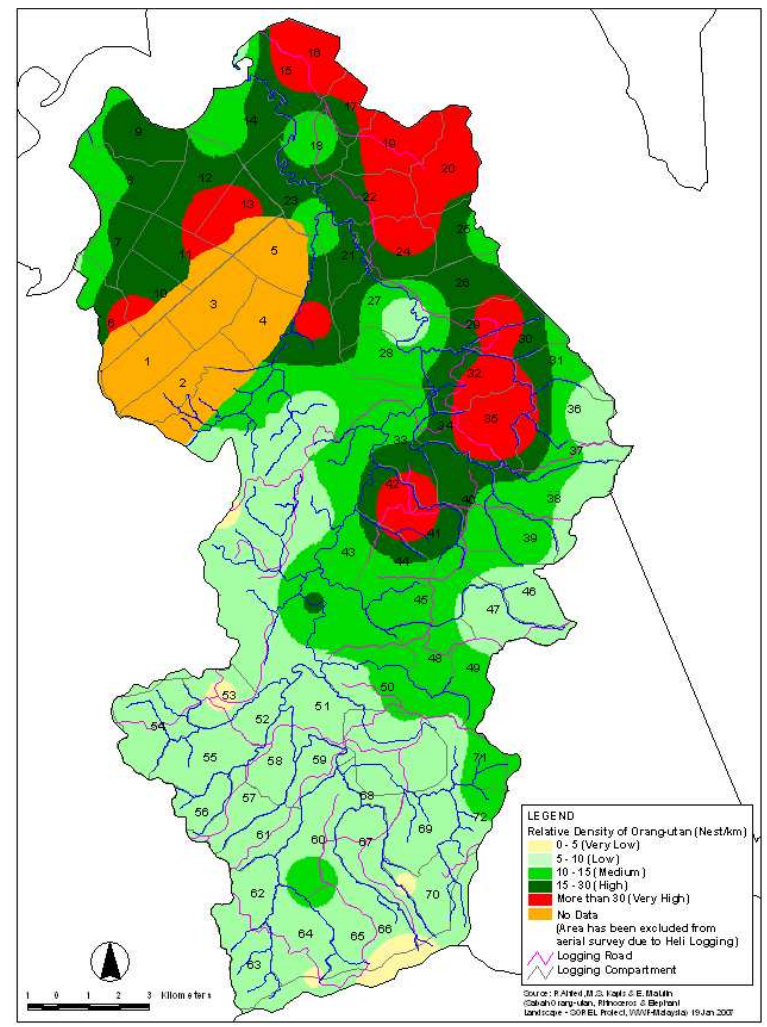

(c)

Fig. 7: Relative distribution density of orang-utan based on orang-utan nest density survey conducted in September 2005, June 2006 and January 2007 respectively. (a) Relative density of orang-utan in Malua FR based on aerial orang-utan nest survey-14 September 2005, (b) Relative density of orang-utan in Malua FR based on aerial orang-utan nest survey-5 June 2006, (c) Relative density of orang-utan in Malua FR based on aerial orang-utan nest survey-18 January 2007

- Ecological competition: The distribution of animal species ecologically is similar to the orang-utan and occurring elsewhere in South-east Asia indicates that orang-utans are not excluded from any area by competition with other species for food or other resources

- Distribution of the natural habitat types: The complex distribution of the natural habitat types resulting in the differences of density and diversity of plant species distribution, influences the distribution of orang-utans

- Productivity of orang-utan foods: Orang-utans feed predominantly on those plant products which require relatively high inputs of nutrients from the soils: fruits and, to a lesser extent, young leaves and flowers. Payne (1987) observed that orangutan distribution and population density are determined by the productivity of food, per unit time and also per unit size of the habitat. There is a positive correlation between the orang-utan population density and the soil fertility as the highest population densities occur on alluvium and on gently-sloping and flat land in the lowlands

The effects of the forest conversion on the orangutan's distribution in the forest landscape: In the Ulu Segama Malua Forest Reserve, four key areas that is identified to have a high density of orang-utan, namely (i) North Ulu Segama, (ii) Northern and Eastern part of Malua Forest Reserve, (iii) Ulu Sungai Danum (Located at the western part of Danum Valley Conservation Areaand Ulu Sungai Segama (located at the southern part of Danum Valley Conservation Area. North Ulu Segama is a fragmented and isolated habitat due to the forest conversion at the northern part of the area and bounded by the Segama River at the southern part. Northern and Eastern part of Malua Forest Reserve also identified as having the high density of orang-utan due to the forest conversion in the lower 
segama's surrounding area. The movement of the orang-utan into the eastern part of Malua is limited due to the existence of the Malua river stretching in a northsouth direction in the middle of Malua Forest Reserve. While, both site in the western and southern part of Danum Valley Conservation area have the high density of orang-utan spatial pattern due to the forest conversion in the western part of Ulu Segama Malua FR (Ulu Sungai Danum), including conversion of the forest habitat at the southern part of Ulu Segama Malua FR.

In the Kinabatangan North area, as shown in Fig. 5, southern part of the both forest reserves consists of relatively high density of orang-utan. Most of the orang-utan in Segaliud Lokan FR and Deramakot FR is concentrated nearby or along the Kinabatangan River and also at the north part of Tangkulap and west part of Segaliud Lokan Forest Reserve. This may be due to the effect of most of the lowland dipterocarp forests of eastern Sabah that were the prime natural orang-utan habitat in the state were heavily exploited and converted to large scale plantation. Since orang-utan cannot survive in extensive large scale mono plantation (tree or oil palm), habitat loss resulting from this process, forcing the orang-utan to concentrate in the southern part of both forest reserves.

In Tabin Wildlife Reserve, as shown in Fig. 5, the south-eastern part of the wildlife reserve consists of relatively high density of orang-utan, especially along the south and east part of the TWR's boundary. This may be due to the effect of most of the lowland dipterocarp forests of the eastern part of TWR that were the prime natural orang-utan habitat in the state was converted to large scale plantation. High density of orang-utan also detected at the North-west part of TWR, where the orang-utans were normally released into this area since several years.

In the Lower Kinabatangan, the orang-utan density is higher especially in (i) Lot 2 of Lower Kinabatangan Wildlife Sanctuary, (ii) west part of Gomantong Forest Reserve, (iii) Western part of Pin Supu Forest Reserve and (iv) area nearby Bod Tai Forest Reserve. Other areas in the Lower Kinabatangan has a low density of orang-utan due to the limitation of the suitable forest habitat and movement of the orang-utan is limited by the river networks.

The effects of the forest conversion on the orangutan population in these habitats, may have altered the suitability of natural habitats (habitat with higher food productivity) for the orang-utan, hence may increase the competition of habitat and food sources.

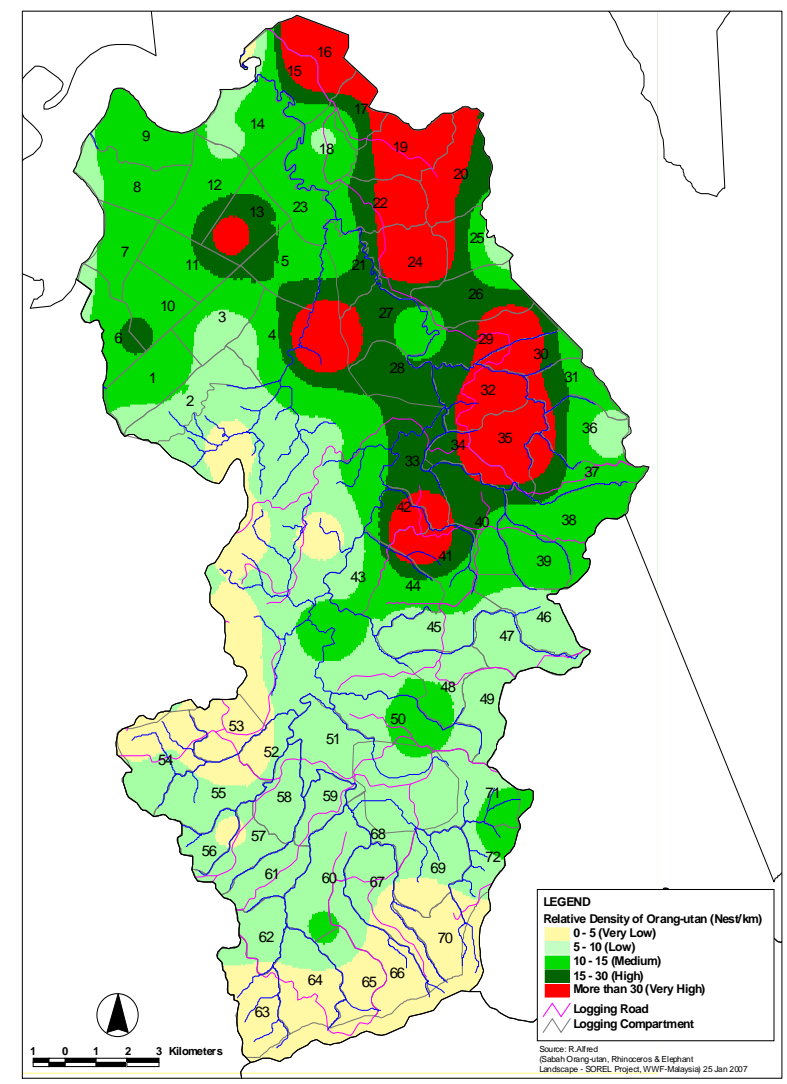

Fig. 8: Relative density of orang-utan in Malua FR based on 3 series of aerial orang-utan nests surveys (September 2005, June 2006, January 2007)

The impact of the logging activities upon the orangutan's movement and habitat utilization: Using the GIS Modeling, (Fig. 8) is developed in order to show areas that consist of high orang-utan density since September 2005 (last 16 mon). Based on Rijksen (1982) and Payne (1987) arguments, it was shown in Fig. 8 that orang-utan distribution in Malua Forest Reserve concentrated especially in a lowland forest and the concentration is merely tend to follow the fruiting season of the Laran and Dipterocarp sp. Relatively small tracts of extreme lowlands are more important for orang-utans than extensive highlands. Previous studies have shown, however, that while orang-utans survive and breed in heavily logged forests, they do tend to prefer patches of forest in good condition in such a landscape.

This is most probably because patches of forest resembling the original condition have a richer array of food plants, as well as protection from stresses such as excessive sunlight and having to walk on the ground. 
Orang-utans are very prominent in some secondary forests, especially in areas dominated by laran trees, because their nests are very obviously-visible in laran trees and orang-utans do eat laran fruits and bark when there is little other food available (mainly over the north monsoon season). Figure 8 also shows that the main river of Malua limits the movement of orang-utan population in east part of Malua FR into west part of Malua. The distribution pattern of the orang-utan density in Malua Forest Reserve depended on the distribution pattern of the trees that preferred by orangutan, especially the laran tree (Noelamarckia cadamba) and Diptercarp sp. trees. During our survey in June 2006, most of the laran trees in Malua FR were facing leaf shading season, where we expect that orang-utan may concentrate at the Dipterocarp sp. trees as their main food sources during that period.

Our survey in January 2007, based on the aerial photos, indicates that most of the laran tree is fruiting and coincidently most of the orang-utan nests are recorded mostly on the laran trees. It is believed that during the January 2007's survey, most of the orangutan concentrated at the laran trees, which is not logged. Based on three series of aerial nest surveys conducted in Malua Forest Reserve, the result shows that:

- The orang-utan population in Malua Forest Reserve is divided physically into two populations by the Malua river

- The distribution of orang-utan in the area where has been logged heavily is relative low, although greater orang-utan nests were recorded in January 2007 (compared to our data gathered in September 2005 and June 2006) but still relative low when we compared to the orang-utan density in the secondary forest

- Our 18 months of monitoring the orang-utan density in Malua Forest Reserve shows that the density of orang-utan in the heavily logged forest is consistently very low (Fig. 8)

The above findings are similar to the observation made by Proud (1976) and Aveling (1982). Proud (1976) and Aveling (1982) observed that fewer orang-utan nests in the logged forests. Line transect sightings of orang-utan recorded by WWF-Malaysia research team indicated that population density of orang-utan in "island" of undisturbed lowland Dipterocarp forest surrounded by logged forest was about two times higher than in extensive areas of undisturbed forest (Payne, 1987). These demonstrate that high density of orang-utan population is always found in the isolated forest habitat. Figure 8 shows that high density of orang-utan population in the northern part is due to the forest habitat are physically isolated by the river, palm oil plantation at the north and forest disturbance such as logging activities.

Determining logging activities' effects on the status of food trees or plant species for orang-utan in the studied areas: Further analyses using the Estimates (Version 8.2.0) is carried out. Based on the Shared Species and Similarity Statistic generated by this software, Jaccard coefficients index shows that only $0.168(16.8 \%)$. This means that the orang-utan in North Ulu Segama consumed almost different species of food plants in years 1974 compared to the data that we gathered in year 2009.

Morisiti-Horn index is only 0.374 because the proportions of the shared species of food trees or plants are not exactly similar. However, the value of the BrayCurtis index is 0.250 which is lower due to the different numbers of available food plants. In years 1974, a total of 97 plants were recorded, while in year 2009 only 71 plants are recorded (Table 4).

\section{CONCLUSION}

The establishment of the relative spatial distribution of orang-utan using a systematic aerial survey enables us to facilitate the assessment and determine the effects of the forest conversions in four main remaining wild orang-utan population landscapes. From the study, we have found that orang-utan distribution density pattern in flat land form especially in lowland Dipterocarp forest is higher compared to the upland forest (more than $750 \mathrm{~m}$ of elevation). We also discovered that the movement of the orang-utan population in the forest habitat is limited due to the river network.

The study is also able to demonstrate the orangutan population movement pattern as a response due to the logging activities. Even though, greater orang-utan nests were recorded in the recently logged area after 8 months, in a longer period of monitoring we however have found out that the orang-utan density in the heavily logged forest is consistently very low.

The effect of logging activities on the status of food trees or plant species for orang-utan in their current forest habitat is very clear where $16.8 \%$ of the plant species recorded in year 2009 was never recorded in year 1974. The condition of the forest forced the orang-utan to adapt or to consume other new and available plants/fruits, due to the absent of at least $25 \%$ the original trees and plants that existed 24 years ago. 
The study demonstrates that the continuous activities of forest conversion and also the degradation of the lowland forest that will eliminate the important habitat for the orang-utan in Sabah, hence forcing the orang-utan to use other available habitat or sources of food in the future.

The only management measures in order to conserve the orang-utan population in Sabah is not by establishment of more protected area but to ensure that the forest habitat could be managed in sustainable way to avoid further degradation and to ensure that their habitat is connected with the large forest landscape.

\section{ACKNOWLEDGEMENT}

We thank WWF-US and WWF-Germany for their financial support to cover the cost for the orang-utan's nest survey by helicopter in order to study the orangutan spatial density status in Tangkulap, Segaliud Lokan and Deramakot Forest Reserves. We also thank WWF-NL and WWF-UK for their financial support in making the orang-utan survey status in Ulu Segama Malua, Tabin Wildlife Reserve and Lower Kinabatangan possible. We also would like to thank the Director of Sabah Forestry Department (Datuk Sam Mannan) and support from Director of Sabah Wildlife Department (Mr. Laurentius Ambu), for granting us the permission to do the aerial survey in these two FMUs and also to thank all Borneo Species Programme's staffs (Mr. Middle Seen Kapis, Mr. Edwin Matulin, Mr. David James, Mr. William Joseph and Mr. Jabanus Miun) for their supports in executing the survey.

\section{REFERENCES}

Altmann, J., 1974. Observational study on behavior: Sampling methods. Anim. Behav., 49: 13-19.

Ancrenaz, M., O. Gimenez, L. Ambu, K. Ancrenaz and P. Andau et al., 2005 Aerial surveys give new estimates for orang-utans in Sabah, Malaysia. PLOS Biol., 3: e3. DOI: 10.1371/journal.pbio.0030003
Aveling, R.J., 1982. Orang-utan Conservation in Sumatra, by Habitat Protection and Conservation Education. In: The Orang-utan, Its Biology and Conservation, De Boer, L.E.M. (Ed.). Hardcover Publisher, ISBN: 9789061937029, pp: 299-315.

Buyya, R. and M. Murshed, 2002. GridSim: A toolkit for the modeling and simulation of distributed resource management and scheduling for grid computing. J. Concurr. Comput.: Pract. Exper., 14: $1175-1220$.

Johnson, A.E., C.D. Knott, B. Pamungkas, M. Pasaribuandrew and J. Marshall, 2004. A survey of the orang-utan (Pongo pygmaeus wurmbii) population in and around gunung palung national park. West Kalimantan, Indonesia based on nest counts. Biol. Conserv., 121: 495-507. DOI: 10.1016/j.biocon.2004.06.002

McKinnon, J.R., 1974. The behavior and ecology of wild orang-utans (Pongo pygmaeus). Anim. Behav., 22: 3-74.

Payne, J., 1987. Surveying orang-utan populations by counting nests from a helicopter: A pilot survey in Sabah. Primate Conserv., 8: 92-103.

Proud, K.R.S., 1976. A study on the effects of logging on orang-utan in the Simunjan Forest Reserve. Primate Conserv., 3: 32-38.

Rijksen, H.D., 1982, How to Save the Mysterious 'Man of the Forest. In: The Orang-utan, Its Biology and Conservation, De Boer, L.E.M., (Ed.). Hardcover Publisher, ISBN: 9789061937029, pp: 317-341. 